\title{
Treadmill exercise enhances motor coordination and ameliorates Purkinje cell loss through inhibition on astrocyte activation in the cerebellum of methimazole- induced hypothyroidism rat pups
}

\author{
Mal-Soon Shin ${ }^{1}$, Bo-Kyun Kim ${ }^{1}$, Shin-Ho Lee ${ }^{1}$, Tae-Soo Kim¹, Yu-Mi Heo', Jun-Ho Choi ${ }^{1}$, \\ Chang-Ju Kim ${ }^{1}$ and Baek-Vin Lim $^{2 *}$ \\ ${ }^{1}$ Department of Physiology, College of Medicine, Kyung Hee Univensity, Seoul, Korea \\ ${ }^{2}$ Department of Exercise Prescription, Division of Leisure \& Sports Science, Dongseo University, Busan, Korea
}

(Received: 2012/06/04, Revised: 2012/06/22, Published online: 2012/06/23)

\begin{abstract}
Thyroid hormones are important for the development of the brain including the cerebellum. In the present study, we investigated the effect of treadmill exercise on the survival of Purkinje neurons and the activation of astrocytes in the cerebellar vermis of hypothyroidism-induced rat pups. On the day of perinatal 14, pregnant rats were divided into two groups ( $\mathrm{n}=5$ in each group): the pregnant control group and the pregnantmethimazole (MMI)-treated group. For the induction of hypothyroidism in the rat pups, MMI was added to the drinking water $(0.02 \% \mathrm{wt} / \mathrm{vol})$, from the day of perinatal 14 to postnatal 49 . After delivery, male rat pups born from the pregnant control group were assigned to the control group. Male rat pups born from the MMI-treated group were divided into the hypothyroidism-induction group, the hypothyroidism-induction with treadmill exercise group, and the hypothyroidism-induction with thyroxine (T4) treatment group $(\mathrm{n}=10 \mathrm{in}$ each group). The rat pups in the exercise group were forced to run on a treadmill for $30 \mathrm{~min}$ once a day for 4 weeks, starting on postnatal day 22 . In the hypothyroidism-induced rat pups, motor coordination was reduced and Purkinje cell death and reactive astrocytes in the cerebellar vermis were increased. Treadmill exercise enhanced motor coordination, increased the survival of Purkinje neurons, down-regulated reactive astrocytes, and enhanced brain-derived neurotrophic factor (BDNF) and receptor tyrosine kinase B (TrkB) expressions in the hypothyroidism-induced rat pups. These results suggest that treadmill exercise has beneficial effects in terms of protecting against thyroid dysfunction by increasing $\mathrm{T} 3$ and T4 and the related protein, BDNF, as well as TrkB, inhibition on astrocyte activation and the reduction of Purkinje cell loss regarding the cerebellum in hypothyroidism rat pups.
\end{abstract}

Keywords: cerebellum, methimazole-induced hypothyroidism, Purkinje neurons, reactive astrocytes, treadmill exercise

\section{INTRODUCTION}

Thyroid hormones, thyroxine (T4) and triiodothyronine (T3), play an important role in brain development including the cerebellum [1,2]. Thyroid hormones also induce the production and maturation of new neurons during brain development [3]. The cerebellum of developing rats is vulnerable to the deficiency of thyroid hormones [4], and several structural anomalies of the cerebellum are associated with hypothyroidism [5].

The cerebellum controls integration of movement, such as motor coordination, movement learning, and postural equilibrium. Purkinje neurons in the cerebellum are closely associated with movement, coordination, and cognitive function [6]. Perinatal hypothyroidism induces retardation regarding the growth and branching of Purkinje cell dendrites, and results in the extensive loss of cerebellar granule cells $[7,8]$. Cerebellar abnormalities by deficiency of the thyroid hormones during the perinatal period implies the reduction in the size and number of cells as well as the abnormal arborization of Purkinje cells $[9,10]$.

Astrocytes are activated following an injury to the central

\footnotetext{
* Corresponding author: Baek-Vin Lim, Tel. 82-51-320-1887, Fax. 82-51-320-1945, Email. todd64@naver.com

(c) 2012 The Korean Society for Exercise Nutrition
} 
nervous system, and they are called reactive astrocytes. Reactive astrocytes are characterized by hypertrophy and proliferation of the astrocytes. Reactive astrocytes have been considered as one of the major impediments to axonal regeneration [11]. Deficiency of the thyroid hormones induces the impairment of cells in the cerebellum, including astrocytes and Golgi epithelial cells $[4,12]$.

Brain-derived neurotrophic factor (BDNF) is a member of the nerve growth factor family regarding neurotrophins, and BDNF is expressed in most brain areas [13]. BDNF is widely presented in the Purkinje cells of the cerebellum [14]. Furthermore, BDNF is a key protein in regulating the maintenance, growth, and survival of neurons [15]. BDNF and the receptor tyrosine kinase $\mathrm{B}$ (TrkB) signaling pathway play important roles in maintaining normal cerebellar function during development [16]. Mice lacking the BDNF \& TrkB receptor genes, typically exhibit impairment of motor coordination [17,18]. Despite these studies involving the cerebellum in response to hypothyroidism, the mechanism regarding Purkinje cell loss and astrogliosis in the cerebellum induced by hypothyroidism, remains unknown.

Exercise is known to restore functions of brain including cerebellum following various brain insults such as traumatic brain injury, post-traumatic stress disorder, Parkinson's disease [19-22]. Thyroid hormones play an important role in the adaptation of an organism to physical exercise and thus may control physical performance [23,24]. Chicharro et al. [24] reported that thyroid hormone levels were increased in the professional cyclists during a 3 week competition. In addition, Ciloglu et al. [25] reported that moderate-intensity exercise induced significant increases in total $\mathrm{T} 3$ and $\mathrm{T} 4$, free T3 and T4, and thyrotrophin (TSH) and high-intensity exercise increased the levels of total T4, free T4, and TSH in humans.

Many studies revealed the effects of exercise on brain function however, the effects of exercise on Purkinje neuronal loss, in relation to astrocyte activation in the cerebellum under hypothyroidism conditions are not clear. In the present study, we investigated the effects of treadmill exercise on Purkinje neuronal loss and reactive astrocytes in the cerebellum using methimazole (MMI)-induced hypothyroidism rat pups.

\section{MATERIALS AND METHODS}

\section{Animals and treatments}

The experimental procedures were conducted in accordance with the animal care guidelines of the National Institutes of
Health (NIH) and the Korean Academy of Medical Sciences. Sprague-Dawley (SD) male rats $(300 \pm 10 \mathrm{~g})$ and female rats $(220 \pm 10 \mathrm{~g})$ were used in this study. Female rats $(n=20)$ were allowed to mate with male rats $(n=10)$ for $24 \mathrm{~h}$. One day later, the female rats were separated from the male rats and housed individually in a plastic home cage at the controlled temperature $\left(20 \pm 2{ }^{\circ} \mathrm{C}\right)$ and the light-dark cycle of $12 \mathrm{~h}$ of light and $12 \mathrm{~h}$ of darkness (light on from 07:00 to 19:00 h). Food and water were made available ad libitum. On the day of perinatal 14 , the pregnant rats were divided into two groups ( $\mathrm{n}=5$ in each group): the pregnant control group and the pregnant MMI-treated group. In order to induce fetal and neonatal hypothyroidism, we used MMI (Sigma Chemical Co., St. Louis, MO, USA). MMI was added to the drinking water $(0.02 \% \mathrm{wt} / \mathrm{vol})$, replaced daily with fresh MMI solution from the day of perinatal 14 to postnatal 49. The rats in the pregnant MMI-treated group were allowed to drink MMI-added water. After delivery, the male rat pups born from the pregnant control group were assigned to the control group. The male rat pups born from the MMI-treated group were divided into the hypothyroidism-induction group, the hypothyroidism-induction with treadmill exercise group, and the hypothyroidism-induction with T4 treatment group ( $\mathrm{n}=$ 10 in each group).

\section{Treadmill exercise protocol}

The rat pups in the exercise group were forced to run on a motorized treadmill for 30 min once a day for 4 weeks, starting on postnatal day 22. The treadmill exercise load consisted of running at 2 meters $/ \mathrm{min}$ for the first $5 \mathrm{~min}$, at 3 meters $/ \mathrm{min}$ for the next $5 \mathrm{~min}$, and then at 8 meters $/ \mathrm{min}$ for the last $20 \mathrm{~min}$ at 0 degree of inclination. In order to avoid possible stress effects, no electric shock was applied to animals during exercise training. The rat pups in the non-exercise groups were left on the treadmill without running for the same period as the exercise group.

\section{Measurement of serum triiodothyronine (T3) and thyroxine (T4)}

Total serum T3 and T4 levels were determined by the rodent T3 enzyme-linked immunosorbent assay (ELISA) test kit (Endocrine Technologies Inc., Newark, CA, USA) and the rodent T4 ELISA test kit (Endocrine Technologies Inc). The absorbance was measured with a microtiter plate reader (Bio-Rad, Hercules, CA, USA) at a test wavelength of 450 nm. 


\section{Grid walking and foot fault test}

Motor coordination was assessed using a grid walking and foot fault test. The rat pups were placed on a stainless steel grid floor $\left(20 \times 40 \mathrm{~cm}\right.$ with a mesh size of $\left.4 \mathrm{~cm}^{2}\right)$ elevated $1 \mathrm{~m}$ above the floor. After a $1 \mathrm{~min}$ observation, the total number of steps was counted. The number of foot faults, when the animals misplaced a forelimb or hindlimb, whereby it fell through the grid, was recorded. Motor coordination was evaluated by the score regarding the number of total steps divided by the number of foot fault steps.

\section{Tissue preparation}

The rat pups were sacrificed after completion of the last treadmill exercise. The animals were anesthetized using Zoletil $50^{\circledR}(10 \mathrm{mg} / \mathrm{kg}$, i.p.; Vibac Laboratories, Carros, France). Then, they were transcardially perfused with $50 \mathrm{mM}$ phosphate-buffered saline (PBS) and fixed with 4\% paraformaldehyde in $100 \mathrm{mM}$ phosphate buffer (PB, pH 7.4). The brains were dissected and postfixed in the same fixative overnight and transferred into a $30 \%$ sucrose solution for cryoprotection. Sagittal sections of $40 \mu \mathrm{m}$ thickness in each section of cerebellum were made with a freezing microtome (Leica, Nussloch, Germany).

\section{Immunofluorescence for the calbindin D-28k-positive and GFAP-positive cells}

Immunofluorescence for the calbindin D-28k-positive and GFAP-positive cells in the cerebellar vermis was performed using the method previously described [21]. The sections were then incubated in $0.05 \mathrm{M}$ PBS for $10 \mathrm{~min}$ and washed 3 times using $0.05 \mathrm{M}$ PBS. Free-floating sections were first incubated in $3 \% \mathrm{H}_{2} \mathrm{O}_{2}$ for $30 \mathrm{~min}$. Next, the sections were incubated in a blocking solution (1\% BSA and $10 \%$ horse serum for calbindin D-28k and GFAP in $0.05 \mathrm{M}$ PBS) for $2 \mathrm{~h}$ at room temperature. The sections were then incubated overnight with a mouse anti-calbindin D-28k antibody (1:3000; Sigma Chemical Co.) or a mouse anti-GFAP antibody (1:500; Chemicon International, Inc., Temecula, CA, USA). Then, the sections were incubated for $2 \mathrm{~h}$ with a fluoresce in isothiocyanate (FITC)-conjugated goat anti-mouse secondary antibody (Jackson Immuno Research Laboratories, West Grove, PA, USA). The sections were then mounted on gelatin-coated glass slides, and the coverslips were mounted using a fluorescent mounting medium (Dako Cytomation, Carpinteria, CA, USA). The slides of the fluorescent images were captured using an epifluorescent microscope (Nikon
Eclipse 50i, Nikon Inc., Melville, NY, USA).

The number of Purkinje-positive cells was counted in a field with dimensions of $1,000 \mu \mathrm{m} \times 400 \mu \mathrm{m}$ in the regions of the cerebellar vermis using Image-Pro ${ }^{\circledR}$ Plus software (Media Cybernetics, Silver Spring, MD, USA). The density of GFAP-positive reactive astrocytes was assessed in a quantitative fashion according to a microdensitometrical method based on optical density using Image-Pro ${ }^{\circledR}$ Plus software (Media Cybernetics). Furthermore, the optical density of GFAP-positive reactive astrocytes was quantified in a field with dimensions of $600 \mu \mathrm{m} \times 700 \mu \mathrm{m}$ and performed in equivalent regions measured for Purkinje neuron counts using Image-Pro ${ }^{\circledR}$ Plus software (Media Cybernetics).

\section{Western blot analysis}

Brain tissues were lysed in an ice-cold whole cell lysate buffer containing $50 \mathrm{mM}$ HEPES ( $\mathrm{pH} 7.5$ ), $150 \mathrm{mM} \mathrm{NaCl}$, $10 \%$ glycerol, $1 \%$ Triton X-100, $1.5 \mathrm{mM}$ magnesium chloride hexahydrate, $1 \mathrm{mM}$ ethyleneglycol-bis-( $\beta$-aminoethyl ether)$\mathrm{N}, \mathrm{N}^{\prime}$-tetraacetic acid (EGTA), $1 \mathrm{mM}$ phenylmethylsulfonyl fluoride (PMSF), $2 \mu \mathrm{g} / \mathrm{ml}$ leupeptin, $1 \mu \mathrm{g} / \mathrm{ml}$ pepstatin, $1 \mathrm{mM}$ sodium ortho vanadate, and $100 \mathrm{mM}$ sodium floride, and the mixture was incubated for $30 \mathrm{~min}$ at $4^{\circ} \mathrm{C}$. Cell debris was removed by microcentrifugation, followed by quick freezing of the supernatant.

The protein concentration was measured using a Bio-Rad colorimetric protein assay kit (Bio-Rad, Hercules, CA, USA). Protein of $30 \mu \mathrm{g}$ was separated on SDS-polyacrylamide gels and transferred onto a nitrocellulose membrane (Whatman, Clifton, NJ, USA). The nitrocellulose membrane was blocked by incubation for $90 \mathrm{~min}$ at room temperature in Tris buffered saline containing $0.1 \%$ Tween 20 (TBST) and 5\% nonfat dried milk (Becton Dickinson, Sparks, MD., USA). Rabbit BDNF and rabbit TrkB antibodies (1:1000; Santa Cruz Biotech., CA, USA) were used as the primary antibody. Horseradish peroxidase-conjugated anti-rabbit BDNF and TrkB antibodies (1:5000; Vector Laboratories) were used as the secondary antibodies. Band detection was performed using the enhanced chemiluminescence (ECL) detection system (Stanta Cruz Botech.). To compare the relative expression of proteins, the detected bands were calculated densitometrically using Image-Pro ${ }^{\circledR}$ Plus software (Media Cybernetics).

\section{Statistical analysis}

All data were analyzed using SPSS 20.0 statistical software (SPSS Inc., Chicago, IL, USA). The data were expressed as the mean \pm standard error of the mean (S.E.M.). For the 
comparison among the groups, One-way ANOVA and Duncan's post-hoc test were performed with $p<0.05$ as an indication of statistical significance.

\section{RESULTS}

\section{Serum T3 and T4 levels}

The level of T3 in the hypothyroidism-induction group was remarkably decreased compared to the control group (2.46 $\pm 0.04 \mathrm{ng} / \mathrm{ml}$ versus $1.38 \pm 0.32 \mathrm{ng} / \mathrm{ml}, p<0.01$ ), whereas treadmill exercise and T3 treatment significantly increased the T3 level of the hypothyroidism-induced rat pups $(2.10 \pm 0.16$ $\mathrm{ng} / \mathrm{ml}$ and $2.45 \pm 0.05 \mathrm{ng} / \mathrm{ml}$, respectively, $p<0.001$ )

The level of T4 in the hypothyroidism-induction group was remarkably decreased compared to the control group (42.20 $\pm 1.76 \mathrm{ng} / \mathrm{ml}$ versus $23.25 \pm 3.56 \mathrm{ng} / \mathrm{ml}, P<0.01$ ), whereas treadmill exercise and $\mathrm{T} 4$ treatment significantly increased the T4 level of the hypothyroidism-induced rat pups $(38.40 \pm 1.20$ $\mathrm{ng} / \mathrm{ml}$ and $49.82 \pm 0.34 \mathrm{ng} / \mathrm{ml}$, respectively, $p<0.001$ )

The present results showed that induction of hypothyroidism decreased T3 and T4 levels, whereas treadmill exercise and $\mathrm{T} 4$ treatment increased the levels of $\mathrm{T} 3$ and $\mathrm{T} 4$ in the hypothyroidism-induced rat pups (Fig. 1).

\section{Grid walking and foot fault test}

The score regarding the grid walking and foot fault test in the hypothyroidism-induction group was remarkably decreased compared with the control group $(19.22 \pm 2.57$

\section{1}

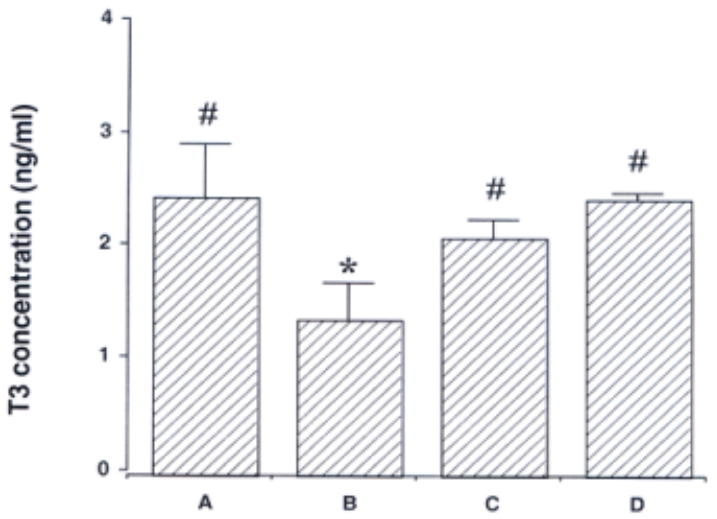

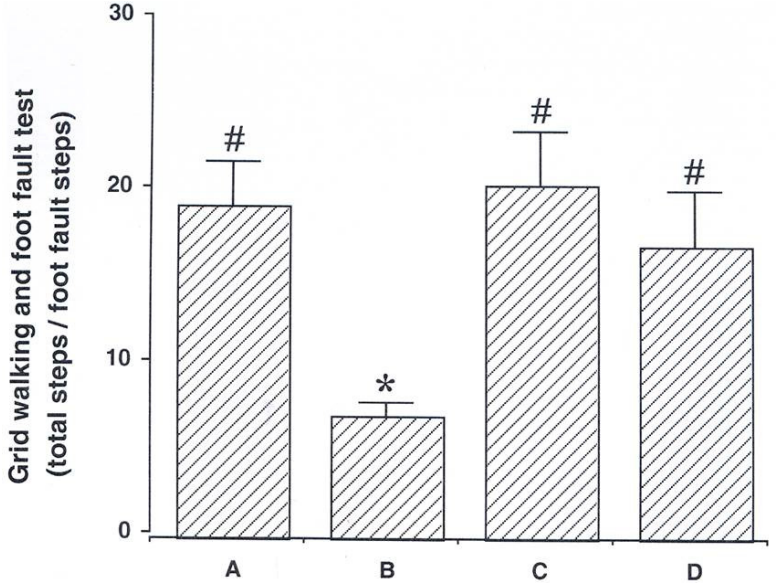

Fig. 2. The effect of treadmill exercise on grid walking and foot fault test. (A) Control group, (B) hypothyroidism-induction group, (C) hypothyroidisminduction with treadmill exercise group, (D) hypothyroidism-induction with T4 treatment group. The data present means \pm S.E.M. ${ }^{*} p<0.05$ in comparison to the control group. ${ }^{\#} p<0.05$ in comparison to the hypothyroidism-induction group.

versus $7.05 \pm 0.85, p<0.05$ ), whereas, treadmill exercise and T4 treatment significantly enhanced the score of the grid walking and foot fault test for the hypothyroidism-induced rat pups $(20.48 \pm 3.12$ and $16.97 \pm 3.21, p<0.05)$.

The present results showed that induction of hypothyroidism decreased motor coordination, whereas treadmill exercise and T4 treatment alleviated hypothyroidism-induced impairment of motor coordination (Fig. 2).

\section{Purkinje neurons in the cerebellar vermis}

The numbers of calbindin-positive cells regarding the anterior region of the cerebellum in the hypothyroidism-
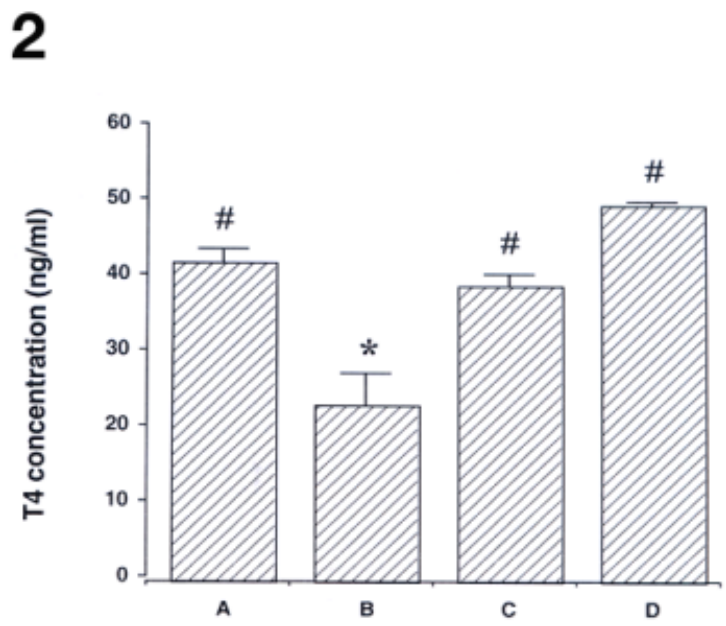

Fig. 1. The effect of treadmill exercise on serum $\mathrm{T} 3$ (1) and $\mathrm{T} 4$ levels (2). (A) Control group, (B) hypothyroidism-induction group, (C) hypothyroidism-induction with treadmill exercise group, (D) hypothyroidism-induction with T4 treatment group. The data present means \pm S.E.M. $* p<0.05$ in comparison to the control group. ${ }^{*} p<0.05$ in comparison to the hypothyroidism-induction group. 
1

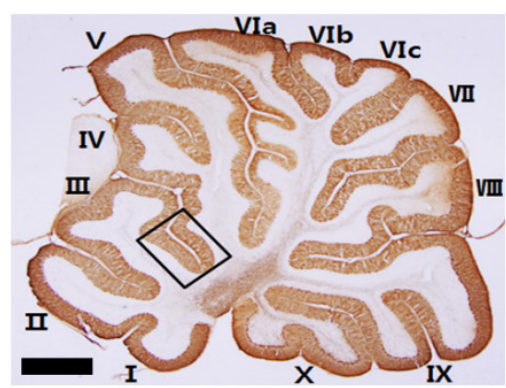

3

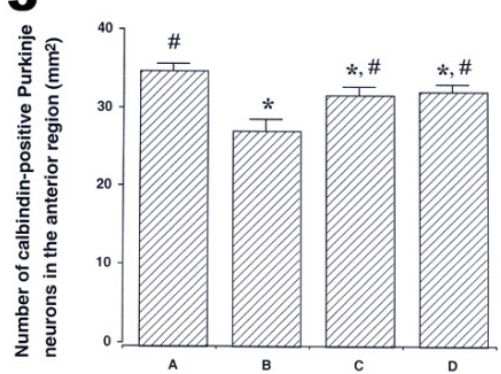

2
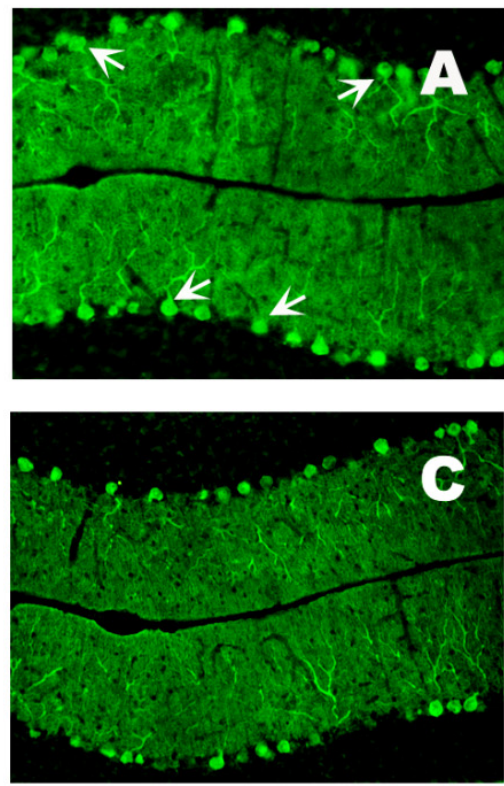
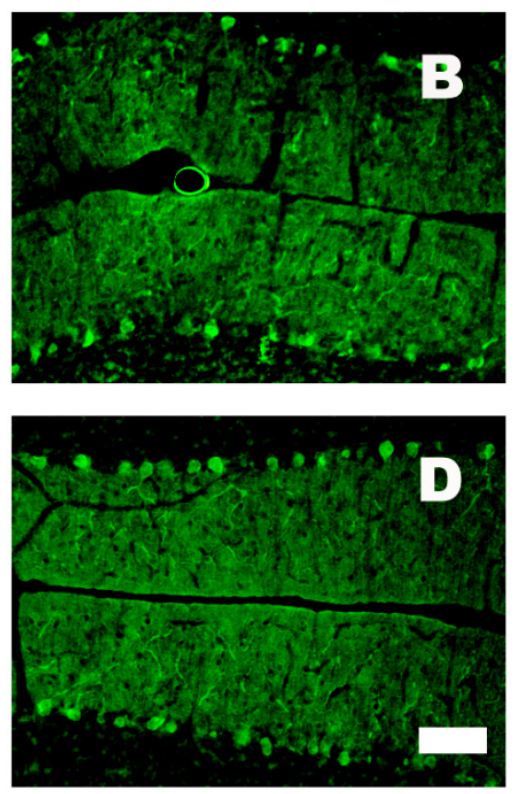

Fig. 3. The effect of treadmill exercise on the number of Purkinje cells in the anterior region of the cerebellum. 1: Photomicrograph of a sagittal section from the cerebellular vermis. The number of Purkinje cells was quantified in a dotted rectangle of the anterior region. Scale bar $=800 \mu \mathrm{m} .2$ : Photomicrographs of calbindin-positive cells in the anterior region of the cerebellum. Scale bar $=50 \mu \mathrm{m}$. 3: The mean number of calbindin-positive cells in each group. (A) Control group, (B) hypothyroidism-induction group, (C) hypothyroidism-induction with treadmill exercise group, (D) hypothyroidism-induction with T4 treatment group. The data present means \pm S.E.M. ${ }^{*} p<0.05$ in comparison to the control group. ${ }_{p}^{*}<0.05$ in comparison to the hypothyroidism-induction group.

1

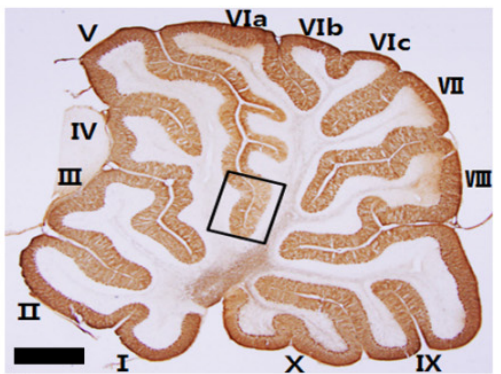

3

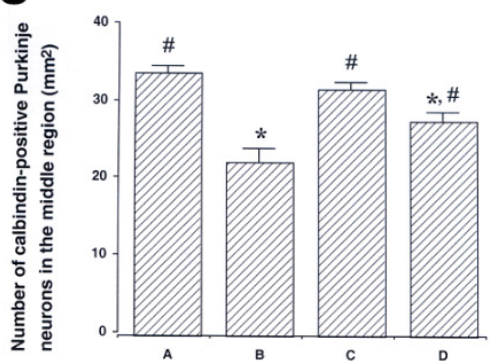

2
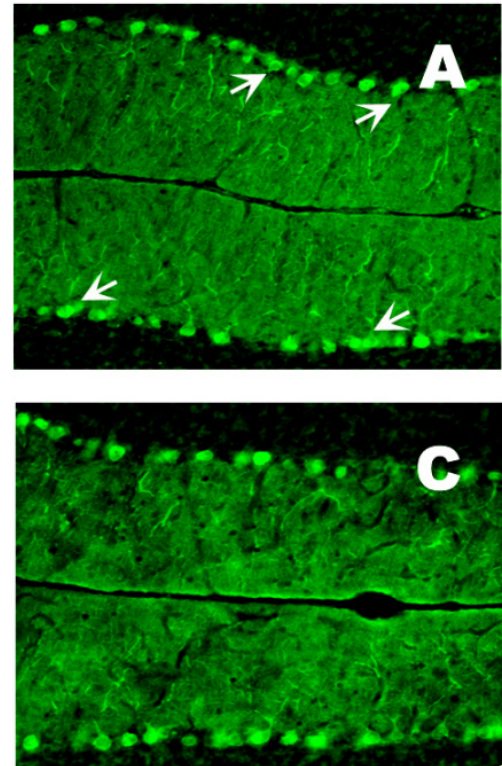
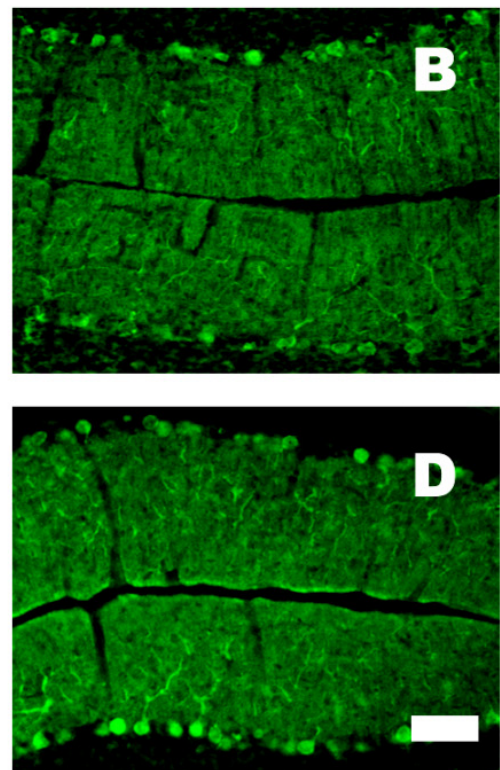

Fig. 4. The effect of treadmill exercise on the number of Purkinje cells in the middle region of the cerebellum. 1: Photomicrograph of a sagittal section from the cerebellular vermis. The number of Purkinje cells was quantified in a dotted rectangle of the middle region. Scale bar $=800 \mu \mathrm{m}$. 2: Photomicrographs of calbindin-positive cells in the middle region of the cerebellum. Scale bar $=50 \mu \mathrm{m}$. 3: The mean number of calbindin-positive cells in each group. (A) Control group, (B) hypothyroidism-induction group, (C) hypothyroidism-induction with treadmill exercise group, (D) hypothyroidism-induction with T4 treatment group. The data present means \pm S.E.M. ${ }^{*} p<0.05$ in comparison to the control group. ${ }^{*} p<0.05$ in comparison to the hypothyroidism-induction group. 
1

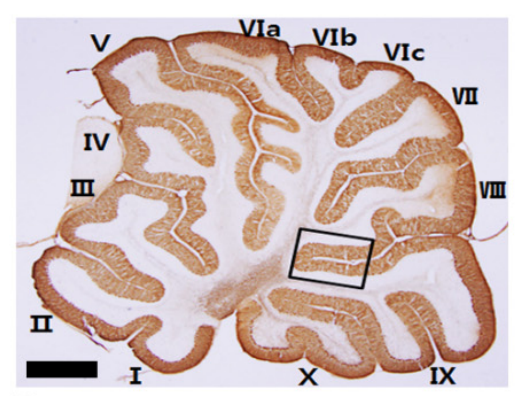

3

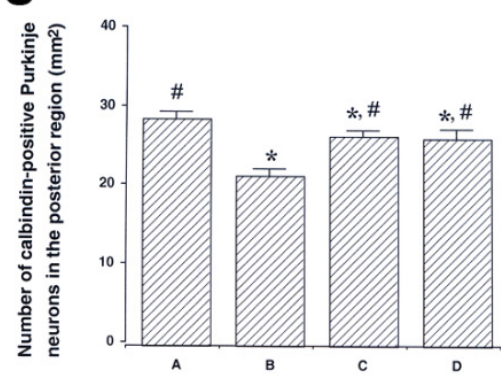

2
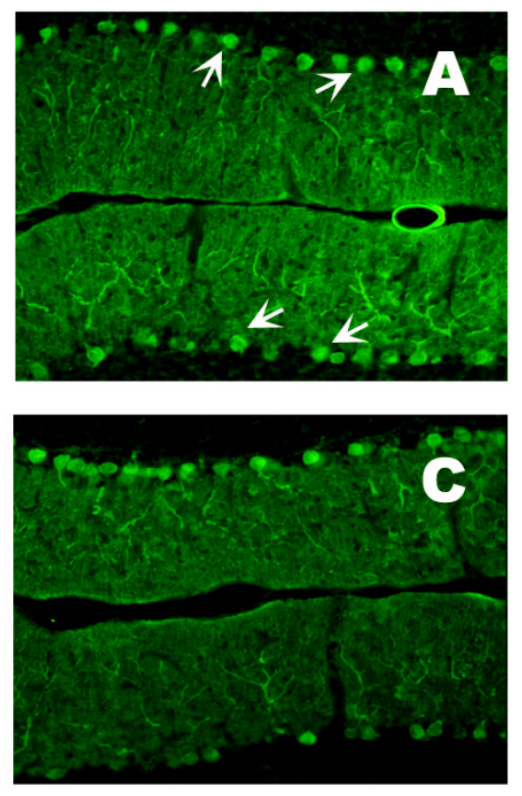
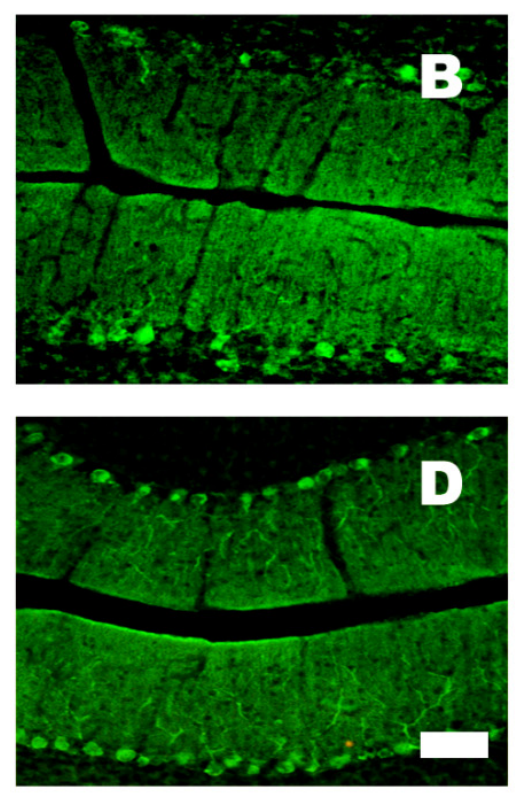

Fig. 5. The effect of treadmill exercise on the number of Purkinje cells in the posterior region of the cerebellum. 1: Photomicrograph of a sagittal section from the cerebellular vermis. The number of Purkinje cells was quantified in a dotted rectangle of the posterior region. Scale bar $=800 \mu \mathrm{m}$. 2: Photomicrographs of calbindin-positive cells in the posterior region of the cerebellum. Scale bar $=50 \mu \mathrm{m}$. 3: The mean number of calbindin-positive cells in each group. (A) Control group, (B) hypothyroidism-induction group, (C) hypothyroidism-induction with treadmill exercise group, (D) hypothyroidisminduction with T4 treatment group. The data present means \pm S.E.M. ${ }^{*} p<0.05$ in comparison to the control group. ${ }^{\sharp} p<0.05$ in comparison to the hypothyroidism-induction group.

1
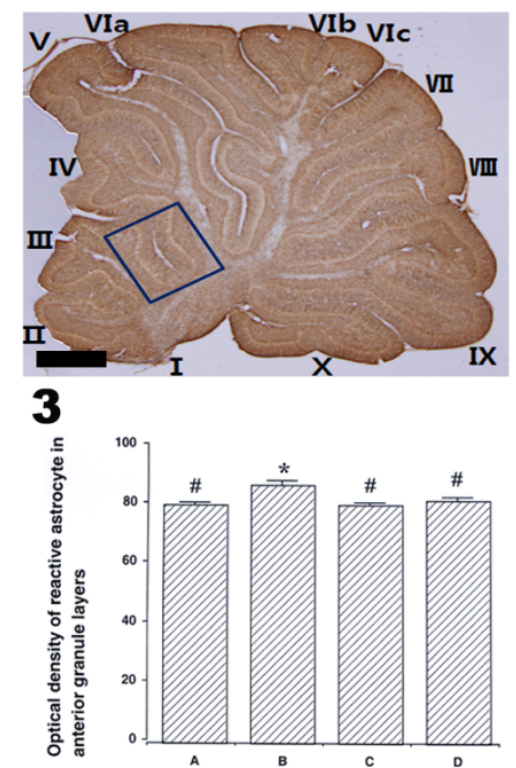

2
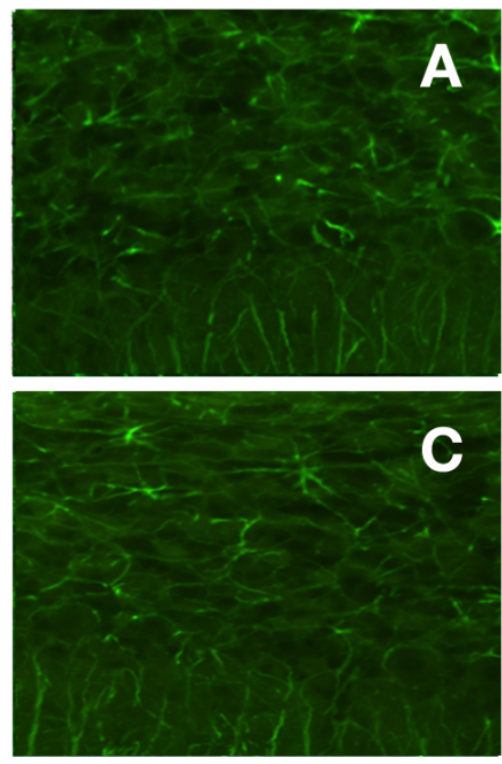
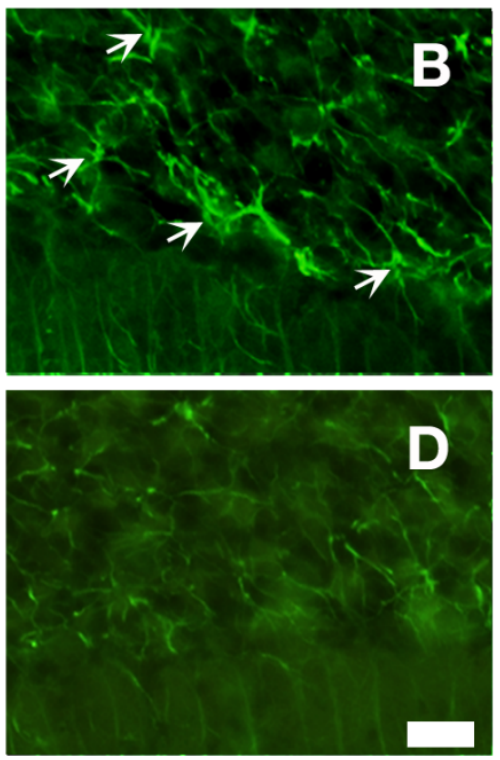

Fig. 6. The effect of treadmill exercise on the reactive astrocyte in the anterior granule layers of the cerebellum. The optical density of GFAP-positive reactive astrocytes was detected at the boundary region between both the molecular and granule layers. 1: Photomicrograph of a sagittal section from the cerebellar vermis. Scale bar $=800 \mu \mathrm{m}$. 2: Photomicrographs of reactive astrocytes in the anterior granule layer of the cerebellum. Scale bar $=100 \mu \mathrm{m}$. 3: The optical density of reactive astrocytes in each group. (A) Control group, (B) hypothyroidism-induction group, (C) hypothyroidism-induction with treadmill exercise group, (D) hypothyroidism-induction with T4 treatment group. The data present means \pm S.E.M. ${ }^{*} p<0.05$ in comparison to the control group. ${ }^{\#} p$ $<0.05$ in comparison to the hypothyroidism-induction group. 
1

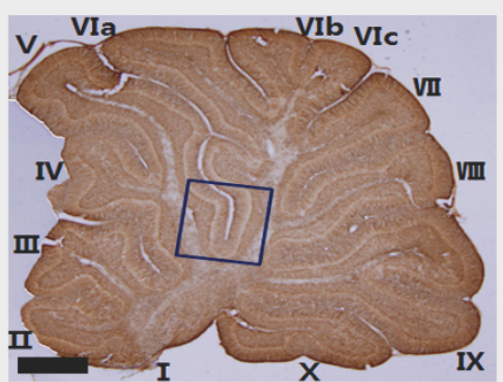

3

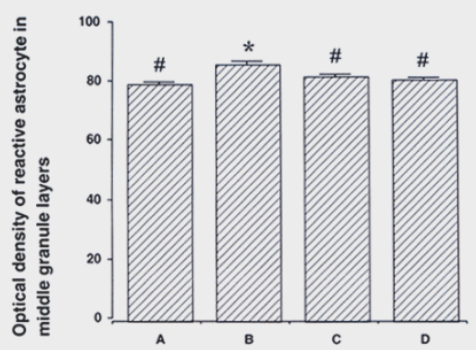

2
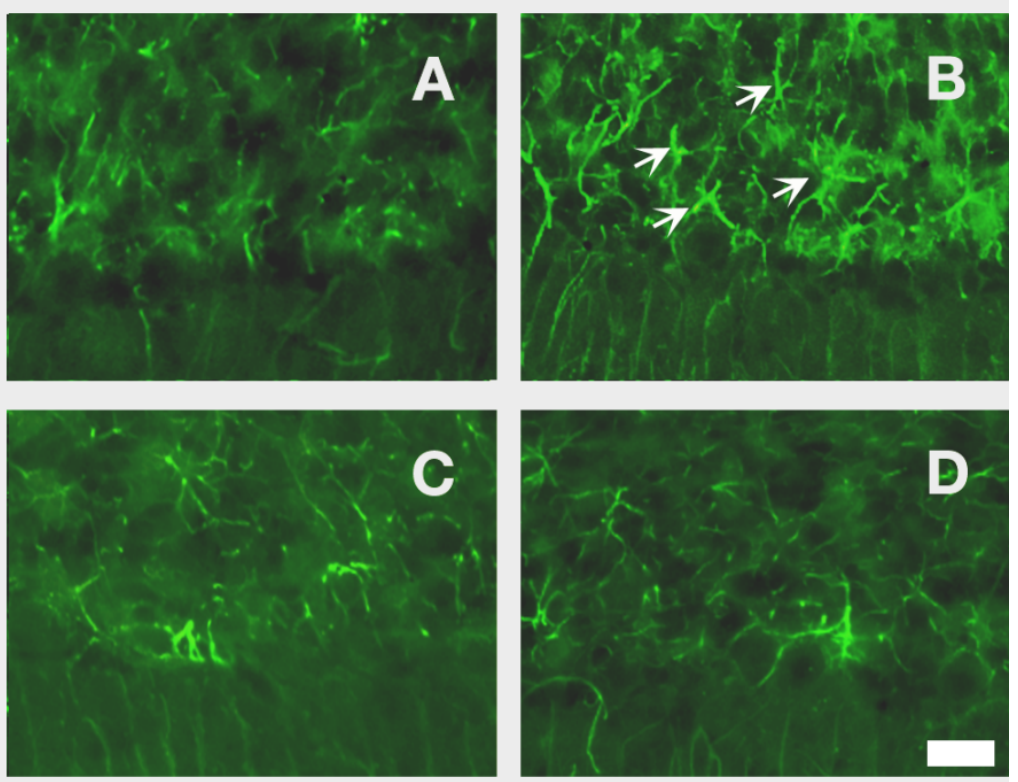

Fig. 7. The effect of treadmill exercise on the reactive astrocyte in the middle granule layers of the cerebellum. The optical density of GFAP-positive reactive astrocytes was detected at the boundary region between both the molecular and granule layers. 1: Photomicrograph of a sagittal section from the cerebellar vermis. Scale bar $=800 \mu \mathrm{m}$. 2: Photomicrographs of reactive astrocytes in the middle granule layer of the cerebellum. Scale bar $=100 \mu \mathrm{m}$. 3 : The optical density of reactive astrocytes in each group. (A) Control group, (B) hypothyroidism-induction group, (C) hypothyroidism-induction with treadmill exercise group, (D) hypothyroidism-induction with T4 treatment group. The data present means \pm S.E.M. ${ }^{*} p<0.05$ in comparison to the control group. ${ }^{*} p$ $<0.05$ in comparison to the hypothyroidism-induction group.
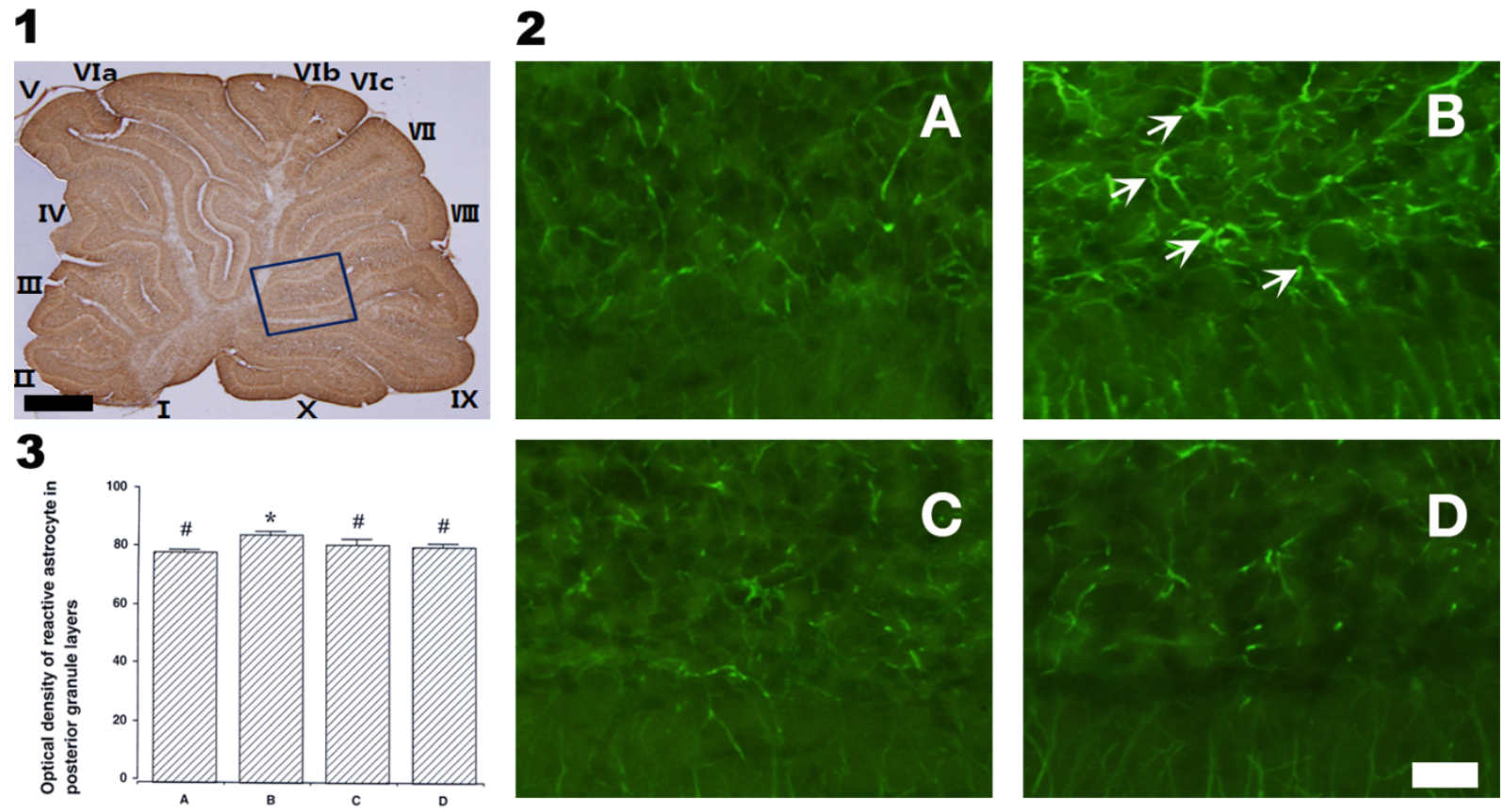

Fig. 8. The effect of treadmill exercise on the reactive astrocytes in the posterior granule layers of the cerebellum. The optical density of GFAP-positive reactive astrocytes was detected at the boundary region between both the molecular and granule layers. 1: Photomicrograph of a sagittal section from the cerebellar vermis. Scale bar $=800 \mu \mathrm{m}$. 2: Photomicrographs of reactive astrocytes in the posterior granule layer of the cerebellum. Scale bar $=100 \mu \mathrm{m}$. 2: Photomicrographs of GFAP-positive reactive astrocytes in the middle region of the cerebellum. 3: The optical density of reactive astrocytes in each group. (A) Control group, (B) hypothyroidism-induction group, (C) hypothyroidism-induction with treadmill exercise group, (D) hypothyroidism-induction with T4 treatment group. The data present means \pm S.E.M. ${ }^{*} p<0.05$ in comparison to the control group. ${ }^{*} p<0.05$ in comparison to the hypothyroidism-induction group. 
induction group was remarkably decreased compared with the control group $\left(35.17 \pm 0.81 / \mathrm{mm}^{2}\right.$ versus $27.44 \pm 1.47 / \mathrm{mm}^{2}, p$ $<0.001$ ), whereas, treadmill exercise and T4 treatment significantly enhanced the numbers of calbindin-positive cells of the hypothyroidism-induced rat pups $\left(32.10 \pm 0.97 / \mathrm{mm}^{2}\right.$ and $\left.32.47 \pm 0.82 / \mathrm{mm}^{2}, p<0.001\right)$.

The numbers of calbindin-positive cells regarding the middle region of the cerebellum in the hypothyroidisminduction group was remarkably decreased compared with the control group $\left(33.89 \pm 0.89 / \mathrm{mm}^{2}\right.$ versus $22.44 \pm 1.72 / \mathrm{mm}^{2}, p$ $<0.001$ ), whereas, treadmill exercise and T4 treatment significantly enhanced the numbers of calbindin-positive cells of the hypothyroidism-induced rat pups $\left(31.86 \pm 0.85 / \mathrm{mm}^{2}\right.$ and $27.77 \pm 1.09 / \mathrm{mm}^{2}, p<0.001$ ).

The numbers of calbindin-positive cells regarding the posterior region of the cerebellum in the hypothyroidisminduction group was remarkably decreased compared with the control group $\left(29.83 \pm 0.82 / \mathrm{mm}^{2}\right.$ versus $21.56 \pm 0.89 / \mathrm{mm}^{2}, p$ $<0.001$ ), whereas, treadmill exercise and T4 treatment significantly enhanced the numbers of calbindin-positive cells of the hypothyroidism-induced rat pups $\left(26.57 \pm 0.90 / \mathrm{mm}^{2}\right.$ and $\left.26.31 \pm 1.12 / \mathrm{mm}^{2}, p<0.001\right)$.

The present results showed that the induction of hypothyroidism decreased the numbers of Purkinje neurons in the cerebellar vermis, whereas treadmill exercise and T4 treatment prevented the hypothyroidism-induced loss of Purkinje neurons in the cerebellar vermis.

\section{Reactive astrocytes in the cerebellar vermis}

The optical density of reactive astrocyte of the granule layers of the anterior cerebellar vermis in the hypothyroidisminduction group was remarkably decreased compared with the control group $(80.50 \pm 0.64$ versus $86.94 \pm 1.44, p<0.001)$, whereas, treadmill exercise and T4 treatment significantly enhanced the optical density of calbindin-positive cells of the hypothyroidism-induced rat pups $(80.31 \pm 0.87$ and $81.98 \pm$ $1.06, p<0.001$ ).

The optical density of reactive astrocyte of the granule layers of the middle cerebellar vermis in the hypothyroidisminduction group was remarkably increased compared with the control group $(79.89 \pm 0.84$ versus $86.64 \pm 1.32, p<0.001)$, whereas, treadmill exercise and $\mathrm{T} 4$ treatment significantly decreased the optical density of calbindin-positive cells of the hypothyroidism-induced rat pups $(82.48 \pm 0.97$ and $81.68 \pm$ $0.79, p<0.001$ ).

The optical density of reactive astrocyte of the granule layers of the posterior cerebellar vermis in the hypothyroidisminduction group was remarkably increased compared with the control group (78.96 \pm 0.99 versus $85.05 \pm 0.94, p<0.01)$, whereas, treadmill exercise and T4 treatment significantly decreased the optical density of calbindin-positive cells of the hypothyroidism-induced rat pups $(81.78 \pm 1.74$ and $80.94 \pm$ 0.87, $p<0.01$ ).

The present results showed that the induction of hypothyroidism increased reactive astrocytes in the granule layers of the cerebellar vermis regions, whereas treadmill exercise and T4 treatment suppressed hypothyroidism-induced astrocyte activation in the granule layers of the cerebellar vermis.

\section{$B D N F$ and TrkB in the cerebellum}

We determined the relative expressions of BDNF and TrkB in the cerebellum. BDNF exists as a mature form (14 kDa). When the level of mature BDNF in the control group was set at 1.00, the level of mature BDNF of the cerebellum in the hypothyroidism-induction group markedly decreased to $0.37 \pm 0.05$ (relative to control cells at 1.00). Whereas, treadmill exercise and $\mathrm{T} 4$ treatment significantly enhanced the level of TrkB of the hypothyroidism-induced rat pups ( 0.69 \pm 0.07 and $0.72 \pm 0.12, p<0.001)$.

When the level of $\operatorname{TrkB}(95 \mathrm{kDa})$ in the control group was set at 1.00, the level of TrkB of the cerebellum in the hypothyroidism-induction group markedly decreased to 0.33 \pm 0.02 (relative to control cells at 1.00). Whereas, treadmill exercise and $\mathrm{T} 4$ treatment significantly enhanced the level of TrkB of the hypothyroidism-induced rat pups $(0.72 \pm 0.07$ and $0.77 \pm 0.08, p<0.001$ ).

In the present results, the expressions of BDNF and TrkB

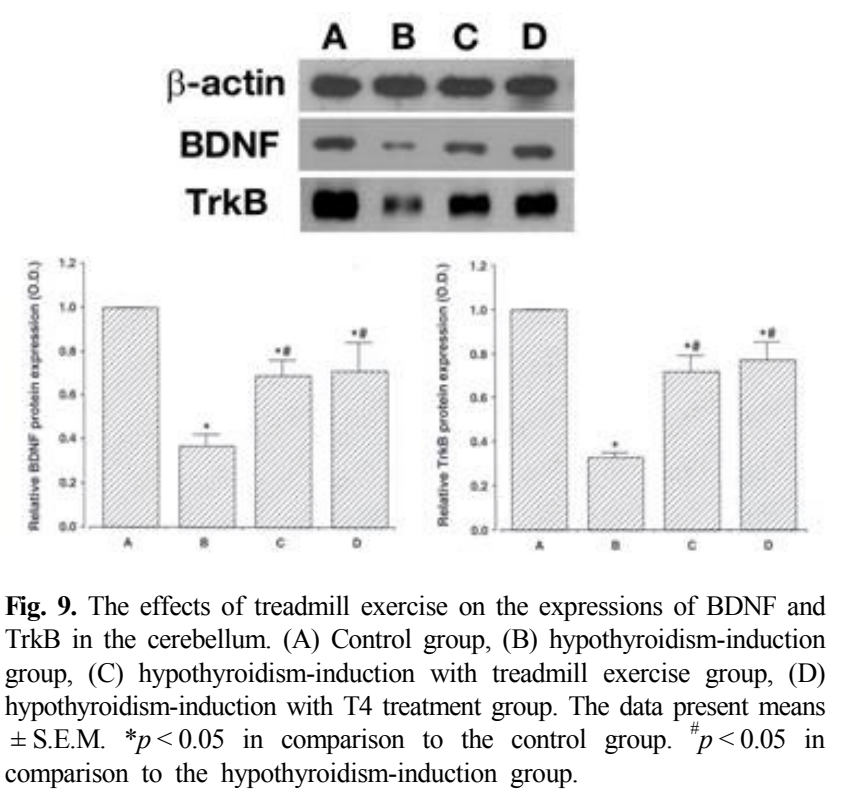


in the cerebellum were decreased by the induction of hypothyroidism, in contrast, treadmill exercise and T4 treatment increased BDNF and TrkB expression in the cerebellum of the hypothyroidism-induced rat pups (Fig. 9).

\section{DISCUSSION}

Deficiency of thyroid hormones reduces visuospatial, sensorimotor, language, auditory, memory, and motor functions [26] through abnormal growth and poor differentiation of the cerebellum [9]. MMI is an anti-thyroid drug, and it has been used for the induction of thyroid dysfunction in rodent models $[27,28]$. MMI inhibits the enzyme thyroperoxidase, which normally acts in thyroid hormone synthesis by oxidizing the anion iodide to iodine, facilitating iodine's addition to tyrosine residues on the hormone precursor thyroglobulin, a necessary step in the synthesis of $\mathrm{T} 3$ and T4 [29]. In order to confirm whether MMI induced hypothyroidism in this study, we determined the levels of T3 and T4. In the present results, serum T3 and T4 levels in the rat pups of the MMI-treated groups were lower than the control rat pups. However, treadmill exercise enhanced T3 and T4 levels in the hypothyroidism-induced rat pups, showing that treadmill exercise ameliorated the severity of hypothyroidism. Hackney and Gulledge [30] reported that T3 and T4 concentrations in the blood were increased after aerobic exercise. Increased thyroid hormones by exercise might be due to the enhancement of catecholamine and glucocorticoid secretion, which affected the adrenergic system and the thyroid axis [31].

The cerebellum modulates the coordination of movements, and cerebellar dysfunction lacks coordination of voluntary movement and causes gait disturbance [32]. Thyroid hormone deficiencies during the fetal and postnatal periods lead to motor dysfunctions [33]. In the present results, hypothyroidism-induced rat pups showed reduced motor coordination, whereas treadmill exercise alleviated hypothyroidism-induced motor disturbance in the rat pups. Exercise can improve motor coordination that engages motor cortex and cerebellum [34].

Calbindin-D-28k is highly expressed in the Purkinje cells, and it has been used as the marker of Purkinje cells in the cerebellum [35]. Purkinje cells are the most important neurons modulating motor coordination and learning [36]. Thyroid hormones activate the proliferation of granule cells in the external granular layer, migrate these cells to the internal granular layer, and induce apoptosis in the internal granular layer during the developmental period [26]. Galton et al. [37] reported that a deficiency of thyroid hormones in the cerebellum delayed the proliferation and migration of granule cells from the external to the internal granular layer. Moreover, a deficiency of thyroid hormones reduces axonal growth and dendritic arborization in the cerebral cortex, visual and auditory cortex, hippocampus, and the cerebellum [38]. In the present results, the numbers of Purkinje neurons in the anterior, middle, and posterior regions of the cerebellar vermis were decreased by hypothyroidism, whereas treadmill exercise significantly alleviated the hypothyroidism-induced loss of Purkinje neurons. Exercise increased blood vessel density and synapses in the Purkinje cells of the cerebellar cortex [39]. Exercise also increased cytochrome oxidase activation reflecting long-term plasticity in the cerebellum [40]. Treadmill exercise alleviated the loss of Purkinje cells in the aged rats [41] and also increased the survival of Purkinje neurons in traumatic brain injury-induced indirect cerebellar injury [21].

Astrocytes are the target cells of the thyroid hormones during brain development [42]. Neonatal hypothyroidism increased the numbers of astrocytes and Bergmann glia in the rat cerebellum [43]. Activation of astrocytes is one of the important pathologic hallmarks of central nervous system injuries [44]. Astrocytes are often considered as a formation of reactive astrocytes around the injured areas after brain trauma induces toxic edema, inflammation, the release of cytotoxins, and glial scar formation, which inhibit axonal regeneration and neuronal survival [45]. A loss in the number of Purkinje neurons in the cerebellum is closely associated with astrocyte activation [46]. Thyroid hormones affect astrocyte morphology, GFAP organization, and glutamine synthase activity and its expression [47,48]. In the present results, the optical densities of reactive astrocytes in the granule layers of the anterior, middle, and posterior regions of the cerebellum were increased by hypothyroidism induced by MMI. Treadmill exercise alleviated the hypothyroidisminduced increase of optical density in the cerebellar vermis. The present results suggest that treadmill exercise increases the survival rate of Purkinje neurons after hypothyroidism via down-regulation of reactive astrocytes.

$\mathrm{BDNF}$ is a neurotrophin involved in neuronal survival and plasticity, and BDNF binds to the high-affinity receptor, TrkB [49]. BDNF-TrkB interaction promotes the survival and differentiation of neurons and this signaling is involved in the modification of neurotransmission and synaptic plasticity regarding the central nervous system $[15,50]$. Exercise is known to increase BDNF expression in the cerebellum [50,51]. In the present results, BDNF and TrkB expressions in the cerebellum were suppressed by hypothyroidism induced by MMI, whereas treadmill exercise enhanced BDNF and 
TrkB expressions in the hypothyroidism rat pups. Enhanced survival of Purkinje neurons and reduced reactive astrocytes might be due to the enhancing effects of treadmill exercise on the neurotrophic factors in the cerebellum. Klintosovaet al. [51] reported that the neuroprotective effect of the cerebellum through exercise correlated with the enhanced expressions of BDNF and TrkB in the cerebellum. Considering these results, it is possible that treadmill exercise affects cell communication between Purkinje cells and astroglial cells through the BDNF-TrkB signaling pathway.

In the present study, hypothyroidism increased Purkinje cell death with the activation of astrocytes in the cerebellar vermis, and resulted in motor coordination disturbance. Treadmill exercise alleviated motor coordination disturbance and increased the survival of Purkinje neurons. Treadmill exercise also down-regulated reactive astrocytes via enhanced BDNF and TrkB expressions in the cerebellum. These effects of treadmill exercise were as potent as T4 treatment. Based on the present results, treadmill exercise may enhance motor coordination and ameliorate Purkinje cell loss through the inhibition of astrocyte activation in the cerebellum of hypothyroidism. Furthermore, treadmill exercise can be considered as a useful therapeutic strategy for hypothyroidism patients.

\section{ACKNOWLEDGEMENTS}

This work was supported by a Korea Research Foundation Grant (KRF-2009-327-G00139).

\section{REFERENCES}

[1] Koibuchi N, Chin WW. Thyroid hormone action and brain development. Trends Endocrinol Metab. 2000;11: 123-8.

[2] Koibuchi N, Jingu H, Iwasaki T, Chin WW. Current perspectives on the role of thyroid hormone in growth and development of cerebellum. Cerebellum. 2003;2: 279-89.

[3] Ambrogini P, Cuppini R, Ferri P, Mancini C, Ciaroni S, Voci A, Gerdoni E, Gallo G. Thyroid hormones affect neurogenesis in the dentate gyrus of adult rat. Neuroendocrinology. 2005;81:244-53.

[4] Morte B, Manzano J, Scanlan TS, Vennström B, Bernal J. Aberrant maturation of astrocytes in thyroid hormone receptor alpha knockout mice reveals an interplay between thyroid hormone receptor isoforms. Endocrinology.
2004; 145:1386-91.

[5] Darras VM. Endocrine disrupting polyhalogenated organic pollutants interfere with thyroid hormone signalling in the developing brain. Cerebellum. 2008;7:26-37.

[6] Ai J, Liu E, Park E, Baker AJ. Structural and functional alterations of cerebellum following fluid percussion injury in rats. Exp Brain Res. 2007;177:95-112.

[7] Nicholson JL, Altman J. The effects of early hypo- and hyperthyroidism on the development of rat cerebellar cortex. I. Cell proliferation and differentiation. Brain Res. 1972;44:13-23.

[8] Madeira MD, Cadete-Leite A, Andrade JP, PaulaBarbosa MM. Effects of hypothyroidism upon the granular layer of the dentate gyrus in male and female adult rats: a morphometric study. J Comp Neurol. 1991;314:171-86.

[9] Koibuchi N. The role of thyroid hormone on cerebellar development. Cerebellum. 2008;7:530-33.

[10] Legrand C, Clos J. Biochemical, immunocytochemical and morphological evidence for an interaction between thyroid hormone and nerve growth factor in the developing cerebellum of normal and hypothyroid rats. Dev Neurosci. 1991;13:382-96.

[11] Ridet JL, Malhotra SK, Privat A, Gage FH. Reactive astrocytes: cellular and molecular cues to biological function. Trends Neurosci. 1997;20:570-77.

[12] Trentin AG. Thyroid hormone and astrocyte morphogenesis. J Endocrinol. 2006;189:189-97.

[13] Friedman WJ, Black IB, Kaplan DR. Distribution of the neurotrophins brain-derived neurotrophic factor, neurotrophin-3, and neurotrophin-4/5 in the postnatal rat brain: an immunocytochemical study. Neuroscience. 1998;84: 101-14.

[14] Kawamoto Y, Nakamura S, Nakano S, Oka N, Akiguchi I, Kimura J. Immunohistochemical localization of brainderived neurotrophic factor in adult rat brain. Neuroscience. 1996;74:1209-26.

[15] Mattson MP, Maudsley S, Martin B. BDNF and 5-HT: a dynamic duo in age-related neuronal plasticity and neurodegenerative disorders. Trends Neurosci. 2004;27: 589-94.

[16] Meng H, Larson SK, Gao R, Qiao X. BDNF transgene improves ataxic and motor behaviors in stargazer mice. Brain Res. 2007;1160:47-57.

[17] Otal R, Martínez A, Soriano E. Lack of TrkB and TrkC signaling alters the synaptogenesis and maturation of mossy fiber terminals in the hippocampus. Cell Tissue Res. 2005;319:349-58.

[18] Schwartz PM, Borghesani PR, Levy RL, Pomeroy SL, 
Segal RA. Abnormal cerebellar development and foliation in $\mathrm{BDNF}^{-/-}$mice reveals a role for neurotrophins in CNS patterning. Neuron. 1997;19: 269-81.

[19] Kim DY, Seo JH, Sung YH, Kim CJ, Jung SY. Physical exercise ameliorates memory impairment in rat pups with maternal lipopolysaccharide-induced cerebral palsy. J Exerc Nutr Biochem. 2011;15:140-47.

[20] Kim TW, Seo JH, Jung SY, Kim DY, Kim CJ, Lee SJ. Treadmill exercise ameliorates post-traumatic stress disorderinduced memory impairment in Sprague-Dawley rats. J Exerc Nutr Biochem. 2011;15:173-82.

[21] Seo TB, Kim BK, Ko IG, Kim DH, Shin MS, Kim CJ, Yoon JH, Kim H. Effect of treadmill exercise on Purkinje cell loss and astrocytic reaction in the cerebellum after traumatic brain injury. Neurosci Lett. 2010;481: 178-82.

[22] Yoon MC, Shin MS, Kim TS, Kim BK, Ko IG, Sung YH, Kim SE, Lee HH, Kim YP, Kim CJ. Treadmill exercise suppresses nigrostriatal dopaminergic neuronal loss in 6-hydroxydopamine-induced Parkinson's rats. Neurosci Lett. 2007;423:12-7.

[23] Chicharro JL, Hoyos J, Bandrés F, Terrados N, Fernández B, Lucía A. Thyroid hormone levels during a 3-week professional road cycling competition. Horm Res. 2001; 56:159-64.

[24] Rone JK, Dons RF, Reed HL. The effect of endurance training on serum triiodothyronine kinetics in man: physical conditioning marked by enhanced thyroid hormone metabolism. Clin Endocrinol (Oxf). 1992;37: 325-30.

[25] Ciloglu F, Peker I, Pehlivan A, Karacabey K, Ilhan N, Saygin O, Ozmerdivenli R. Exercise intensity and its effects on thyroid hormones. Neuro Endocrinol Lett. 2005; 26:830-4.

[26] Zoeller RT, Rovet J. Timing of thyroid hormone action in the developing brain: clinical observations and experimental findings. J Neuroendocrinol. 2004;16: 809-18.

[27] Kala N, Ravisankar B, Govindarajulu P, Aruldhas MM. Impact of foetal-onset hypothyroidism on the epididymis of mature rats. Int J Androl. 2002;25:139-48.

[28] Ramos S, Goya L, Martin MA, Escrivá F, Pascual-Leone AM. Influence of hypothyroidism on circulating concentrations and liver expression of IGF-binding proteins mRNA from neonatal and adult rats. J Endocrinol. 2002;172:363-73.

[29] Taurog A, Dorris ML, Guziec FS Jr. Metabolism of 35Sand 14C-labeled1-methyl-2-mercaptoimidazolein vitro and in vivo. Endocrinology. 1989; 124:30-9.
[30] Hackney AC, Gulledge T. Thyroid hormone responses during an 8-hour period following aerobic and anaerobic exercise. Physiol Res. 1994;43:1-5.

[31] Mena P, Maynar M, Campillo JE. Changes in plasma enzyme activities in professional racing cyclists. $\mathrm{Br} \mathrm{J}$ Sports Med. 1996;30:122-124.

[32] Taroni F, DiDonato S. Pathways to motor incoordination: the inherited ataxias. Nat Rev Neurosci. 2004;5:641-55.

[33] Carranza D, Van Vliet G, Polak M. Congenital hypothyroidism, Ann Endocrinol (Paris). 2006;67:295-302.

[34] Pietropaolo S, Feldon J, Alleva E, Cirulli F, Yee BK. The role of voluntary exercise in enriched rearing: a behavioral analysis. Behav Neurosci. 2006;120:787-803.

[35] Haworth R, McCormack N, Selway S, Pilling AM, Williams TC. Calbindin D-28 and microtubule-associated protein-2: their use as sensitive immunohistochemical markers of cerebellar neurotoxicity in a regulatory toxicity study. Exp Toxicol Pathol. 2006;57:419-26.

[36] Ohkawa N, Hashimoto K, Hino T, Migishima R, Yokoyama M, Kano M, Inokuchi K. Motor discoordination of transgenic mice overexpressing a microtubule destabilizer, stathmin, specifically in Purkinje cells. Neurosci Res. 2007;59:93-100.

[37] Galton VA, Wood ET, St Germain EA, Withrow CA, Aldrich G, St Germain GM, Clark AS, St Germain DL. Thyroid hormone homeostasis and action in the type 2 deiodinase-deficient rodent brain during development. Endocrinology. 2007;148:3080-8.

[38] Gong J, Dong J, Wang Y, Xu H, Wei W, Zhong J, Liu W, Xi Q, Chen J. Developmental iodine deficiency and hypothyroidism impair neural development, up-regulate caveolin-1, and down-regulate synaptophysin in rat hippocampus. J Neuroendocrinol. 2010;22:129-39.

[39] Black JE, Isaacs KR, Anderson BJ, Alcantara AA, Greenough WT. Learning causes synaptogenesis, whereas motor activity causes angiogenesis, in cerebellar cortex of adult rats. PNSA U S A. 1990;87:5568-72.

[40] Garifoli A, Cardile V, Maci T, Perciavalle V. Exercise increases cytochrome oxidase activity in specific cerebellar areas of the rat. Archives Italiennes de Biologie. 2003; 141:181-7.

[41] Larsen JO, Skalicky M, Viidik A. Does long-term physical exercise counteract age-related Purkinje cell loss? A stereological study of rat cerebellum. J Comp Neurol. 2000;428:213-22.

[42] Gould E, Frankfurt M, Westlind-Danielsson A, McEwen BS. Developing forebrain astrocytes are sensitive to thyroid hormone. Glia. 1990;3:283-92. 
[43] Clos J, Legrand C, Legrand J. Effects of thyroid state on the formation and early morphological development of Bergmann glia in the developing rat cerebellum. Dev Neurosci 1980;3:199-208.

[44] Chen Y, Swanson RA. Astrocytes and brain injury. J Cereb Blood Flow Metab. 2003;23:137-49.

[45] Myer DJ, Gurkoff GG, Lee SM, Hovda DA, Sofroniew MV. Essential protective roles of reactive astrocytes in traumatic brain injury. Brain. 2006; 129:2761-72.

[46] Park E, McKnight S, Ai J, Baker AJ. Purkinje cell vulnerability to mild and severe forebrain head trauma. J Neuropathol Exp Neurol. 2006; 65:226-34.

[47] Calloni GW, Alvarez-Silva M, Vituri C, Trentin AG. Thyroid hormone deficiency alters extracellular matrix protein expression in rat brain. Dev Brain Res. 2001;126: 121-4.

[48] Trentin AG, Mendes de Aguiar CBN, Garcez RC,
Alvarez-Silva M. Thyroid hormone modulates the extracellular matrix organization and expression in cerebellar astrocyte: effects on astrocyte adhesion. Glia. 2003;42: 359-69.

[49] Givalois L, Marmigère F, Rage F, Ixart G, Arancibia S, Tapia-Arancibia L. Immobilization stress rapidly and differentially modulates BDNF and TrkB mRNA expression in the pituitary gland of adult male rats. Neuroendocrinology. 2001;74:148-59.

[50] Klintsova AY, Dickson E, Yoshida R, Greenough WT. Altered expression of BDNF and its high-affinity receptor TrkB in response to complex motor learning and moderate exercise. Brain Res. 2004;1028:92-104.

[51] Neeper SA, Gómez-Pinilla F, Choi J, Cotman CW. Physical activity increases mRNA for brain-derived neurotrophic factor and nerve growth factor in rat brain. Brain Res. 1996;726:49-56. 